\title{
Modelling axisymmetric cod-ends made of different mesh types
}

\author{
D Priour $^{1 *}$, B Herrmann ${ }^{2}$, and F G O'Neill ${ }^{3}$ \\ ${ }^{1}$ French Institute of Marine Research (IFREMER), Plouzane Cedex, France \\ ${ }^{2}$ Danish Institute for Fisheries Research (DIFRES), North Sea Centre, Hirtshals, Denmark \\ ${ }^{3}$ Fisheries Research Services Marine Laboratory, Aberdeen, UK
}

The manuscript was received on 9 June 2008 and was accepted after revision for publication on 30 September 2008.

DOI: 10.1243/14750902JEME120

\begin{abstract}
Cod-ends are the rearmost part of trawl fishing gears. They collect the catch, and for many important species it is where fish selection takes place. Generally speaking they are axisymmetric, and their shape is influenced by the catch volume, the mesh shape, and the material characteristics. The shape of cod-ends is of importance as it determines mesh opening and consequently influences the selectivity of fish from the cod-end. Selectivity is the process whereby a gear retains large fish and releases small ones. In recent years, as many fish stocks have become more threatened, understanding the selectivity process has become more important. This paper presents a model of the deformation of an axisymmetric cod-end. The twine tension and the catch pressure acting on the knots of each mesh along the cod-end profile are calculated, and a Newton-Raphson scheme is used to estimate the equilibrium position of the netting. The software package developed to solve this problem is freely available. Comparisons are carried out with a previous model and experimental data.
\end{abstract}

Keywords: cod-ends, mesh shape, trawl selectivity, simulation, bycatch reduction, twine tensions, catch force

\section{INTRODUCTION}

In general, commercial fishing operations are directed towards the capture of larger-size classes. In most instances, the capture of the target species is accompanied with an, often large, incidental catch of fish that are either below the statutory minimum commercial landing size or are non-target species. Bycatch constitutes approximately one-third of the total marine harvest worldwide, amounting to roughly 25 million tonnes of catch [1]. There is no doubt that these fisheries are catching a large proportion of juvenile fish, and this is one of the main reasons that many stocks are below safe limits.

There is an urgent need to develop methods for reducing such wasteful bycatch. Considerable effort has been directed towards improving the selectivity of trawls, and many experimental trials have taken place. These trials are generally very expensive and,

*Corresponding author: IFREMER, BP 70, Plouzane 29280,

France.email: daniel.priour@ifremer.fr owing to the large number of uncontrollable biological and environmental parameters, require a large number of repeat experiments to perform studies of sufficient statistical power. Consequently, the results of these types of trial are often inconclusive.

A promising way to proceed is to use predictive models of cod-end selectivity such as PRESEMO [2, 3]. PRESEMO is an individual-based structural model of the selection process in the cod-end of a trawl fishing gear. It models different populations of fish entering the cod-end during a haul, where each fish is assigned a range of biological and behavioural characteristics related to its morphology and its potential to make escape attempts. An escape attempt is considered successful if the fish can pass through the mesh nearest to where the escape attempt takes place. Fish that do not escape become exhausted and fall back and become part of the catch. In addition to the biological and behavioural information, PRESEMO requires information on the distribution of mesh opening along the cod-end and how it may vary during a tow as the catch builds up 
$[\mathbf{4}, \mathbf{5}]$. The extent to which the cod-end meshes open is a function of the cod-end design, the catch size, and the cod-end hydrodynamics. In recent years, a number of models of netting deformation have been developed, two of which have been used in conjunction with PRESEMO, to predict cod-end geometry and hence the openness of the meshes. O'Neill [6, 7] derives differential equations that govern the geometry of axisymmetric cod-ends for a range of different mesh shapes, whereas Priour [8, 9] has developed a more general three-dimensional finite element method (FEMNET) model of netting deformation. Both of these models can take into account the elasticity and bending stiffness of the component twines, cod-ends of a range of mesh shapes, and the hydrodynamic forces that act on the netting material and cod-end catch. The accuracy of their predictions are compared by O'Neill and Priour [10] and is found to be very good. Furthermore, O'Neill and Herrmann [3] have used these models with PRESEMO to predict the selectivity of a large range of cod-ends of varying design and validated the selectivity predictions with experimental data.

In this paper, a further axisymmetric model of cod-end geometry is developed by looking at the force balance on the twine elements on a row along the cod-end length. The advantage of this model over those above is that it is easy to implement and its solution does not depend on the use of licensed software. Hence, it will be freely available and easy to incorporate into simulation packages such as PRESEMO.

\section{FORCES ACTING ON THE COD-END NETTING}

The geometries of cod-ends made of diamond-, square-, rectangular-, and kite-shaped netting are investigated. By assuming axisymmetry, the cod-end geometry can be determined by examining the nodes belonging to one row of twine along the cod-end length (Fig. 1). The approach consists of three steps. Firstly, an initial position of these nodes, consistent with the boundary conditions, must be defined. Then, the forces acting on these nodes are calculated. Finally, using the Newton-Raphson method, the equilibrium position of these nodes is evaluated.

The forces that act on the cod-end are the twine tensions and the hydrodynamic forces. As shown by O'Neill and O'Donoghue [11], the hydrodynamic forces that act on the unblocked netting are negligible in comparison with the pressure forces acting on the netting where the catch blocks the
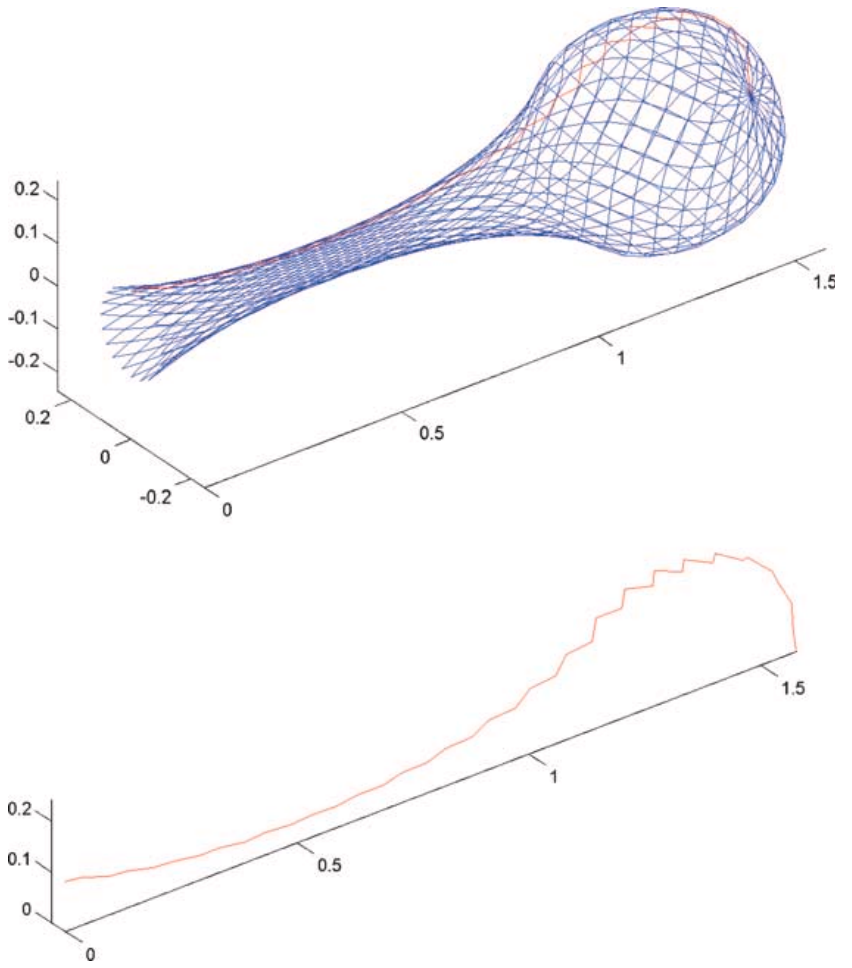

Fig. 1 Diamond-mesh cod-end (top), and the twines along a meridian that are examined (bottom). Axes in $\mathrm{m}$

meshes. Consequently, it is only necessary to consider the twine tensions and the pressure forces that act in the region of the catch.

\subsection{Twine tensions}

\subsubsection{Diamond-mesh cod-ends}

The nodes along the calculated twine are numbered from 1 to $n$ (Fig. 2). They are defined by the $x$ coordinate along the axis of the cod-end and by $r$,

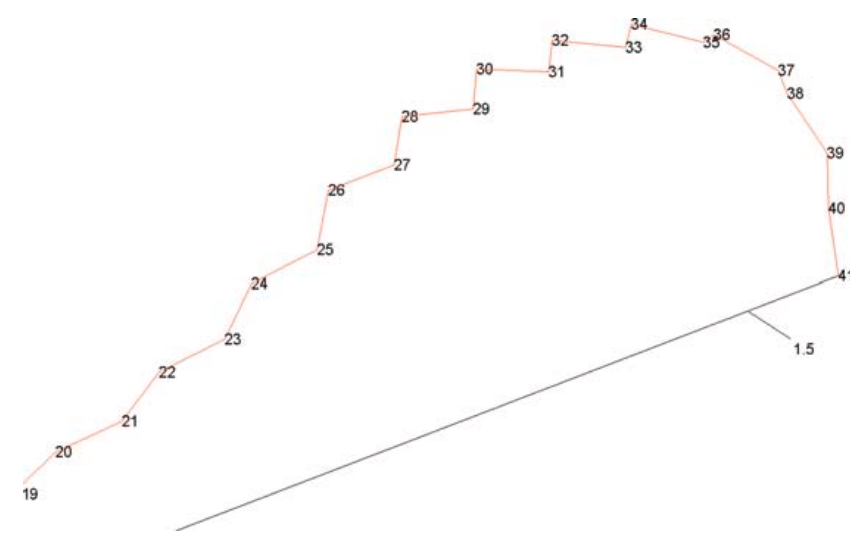

Fig. 2 Nodes along the calculated twine, numbered from 1 to $n$ 
the radial coordinate. The nodes with the odd number are on the plane defined by $y=0$, and the nodes with even numbers are such that $y>0$. With these definitions, the Cartesian coordinates for a node $i$ is

$$
\left(\begin{array}{c}
x_{i} \\
0 \\
r_{i}
\end{array}\right) \text { when } i \text { is odd }
$$

and

$$
\left(\begin{array}{c}
x_{i} \\
r_{i} \sin \theta \\
r_{i} \cos \theta
\end{array}\right) \text { when } i \text { is even }
$$

where

$$
\theta=\frac{\pi}{n_{\mathrm{m}}}
$$

is the angle defined by one row in the plane normal to the cod-end axis, $n_{\mathrm{m}}$ is the number of meshes around the circumference, and

$$
r_{i}=\sqrt{y_{i}^{2}+z_{i}^{2}}
$$

From these coordinates, the length of the twine between two consecutives nodes $(i, i+1)$ is

$$
l_{i}=\sqrt{\left(x_{i}-x_{i+1}\right)^{2}+r_{i}^{2}+r_{i+1}^{2}-2 r_{1} r_{i+1} \cos \theta}
$$

and, in the hypothesis of elastic twine, the magnitude of the tension in the twine is

$$
T_{i}=E A \frac{l_{i}-l_{0}}{l_{0}}
$$

where $E$ is Young's modulus of the material of the twine $\left(\mathrm{N} / \mathrm{m}^{2}\right), A$ is the twine cross-sectional area $\left(\mathrm{m}^{2}\right)$, and $l_{0}$ is the unstretched length (m); $E A$ is the stiffness of the twine $(\mathrm{N})$, which is set to zero when the twine is in compression. Accordingly, the tension vectors acting on node $i$ (in Cartesian coordinates) are

$$
\begin{gathered}
T_{i-1}=-\frac{T_{i-1}}{l_{i-1}}\left(\begin{array}{c}
x_{i}-x_{i-1} \\
y_{i}-y_{i-1} \\
z_{i}-z_{i-1}
\end{array}\right) \\
\text { and } T_{i}=\frac{T_{i}}{l_{i}}\left(\begin{array}{c}
x_{i+1}-x_{i} \\
y_{i+1}-y_{i} \\
z_{i+1}-z_{i}
\end{array}\right)
\end{gathered}
$$

To calculate the axial and radial components of these forces on each extremity of the twine, these vectors are multiplied by the unit axis and radial vectors (Fig. 3), where the unit axis vector is

$$
\frac{x_{i}}{\left|x_{i}\right|}=\left(\begin{array}{l}
1 \\
0 \\
0
\end{array}\right)
$$

and the unit radial vector is

$$
\frac{r_{i}}{\left|r_{i}\right|}=\left(\begin{array}{l}
0 \\
0 \\
1
\end{array}\right) \quad \text { if } i \text { is odd }
$$

and

$$
\left(\begin{array}{c}
0 \\
\sin \theta \\
\cos \theta
\end{array}\right) \text { if } i \text { is even }
$$

\subsubsection{Square-mesh cod-ends}

Square-mesh cod-ends have twines that are either in the circumferential or in the meridional direction (Fig. 4). The circumferential twines are in planes that are normal to the cod-end axis, while the meridional twines are in planes including the cod-end axis.

Twine tension along the circumference. At a node $i$ there are two circumferential twines, both of which have length

$$
l_{\mathrm{c}, i}=2 r_{i} \sin \frac{\alpha}{2}
$$

where $\alpha$ is the angle at the axis in the circumferential plane shown in Fig. 5 and is defined as

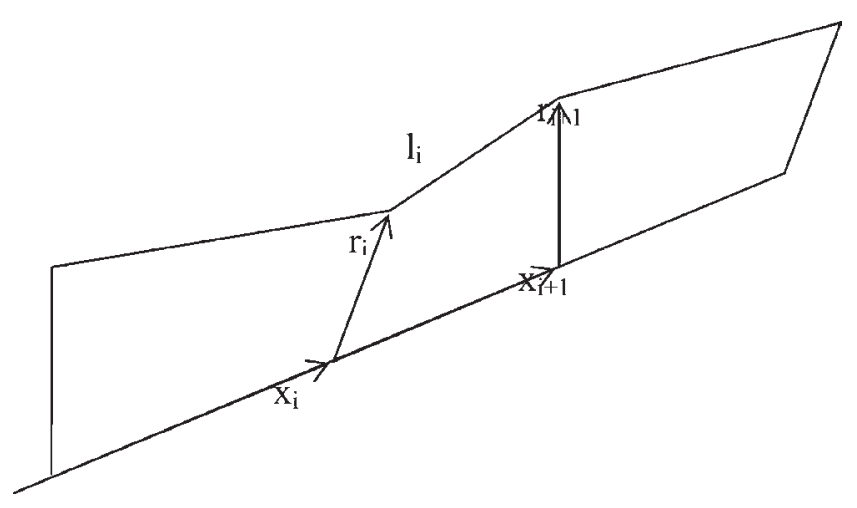

Fig. 3 Twines on the diamond-mesh cod-end, with the axial and radial vectors 


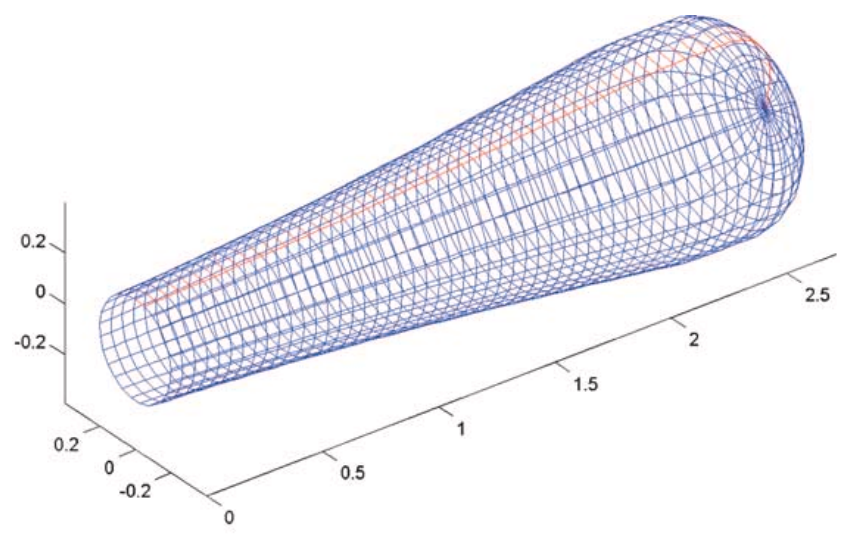

The corresponding vector in Cartesian coordinates is

$$
\boldsymbol{T}_{\mathrm{c}, i}=T_{\mathrm{c}, i}\left(\begin{array}{c}
0 \\
\pm \cos \frac{\alpha}{2} \\
-\sin \frac{\alpha}{2}
\end{array}\right)
$$

which has no component in the direction of the codend axis and where the sign of the $y$ component depends on which of the two twines is being examined.

Twine tension along the meridian. The length of twine $i$ along the meridian is (Fig. 6)

$$
l_{\mathrm{m}, i}=\sqrt{\left(x_{i+1}-x_{i}\right)^{2}+\left(r_{i+1}-r_{i}\right)^{2}}
$$

and the magnitude of the tension acting between the nodes $i$ and $i+1$ is

$$
T_{\mathrm{m}, i}=E A \frac{l_{\mathrm{m}, i}-l_{0}}{l_{0}}
$$

Hence, the tension vectors acting in the direction of the meridian acting on node $i$ are

Fig. 4 Square-mesh cod-end (top), and the twines along a meridian that are examined (bottom). Axes in $\mathrm{m}$

$$
\alpha=\frac{2 \pi}{n_{\mathrm{b}}}
$$

where $n_{\mathrm{b}}$ is the number of mesh bars in circumference. As before, the magnitude of the tension in these twines is

$$
T_{\mathrm{c}, i}=E A \frac{l_{\mathrm{c}, i}-l_{0}}{l_{0}}
$$

$$
\begin{aligned}
& \boldsymbol{T}_{\mathrm{m}, i-1}=-\frac{T_{\mathrm{m}, i-1}}{l_{\mathrm{m}, i-1}}\left(\begin{array}{c}
x_{i}-x_{i-1} \\
y_{i}-y_{i-1} \\
0
\end{array}\right) \\
& \text { and } \quad \boldsymbol{T}_{\mathrm{m}, i}=\frac{T_{\mathrm{m}, i}}{l_{\mathrm{m}, i}}\left(\begin{array}{c}
x_{i+1}-x_{i} \\
y_{i+1}-y_{i} \\
0
\end{array}\right)
\end{aligned}
$$

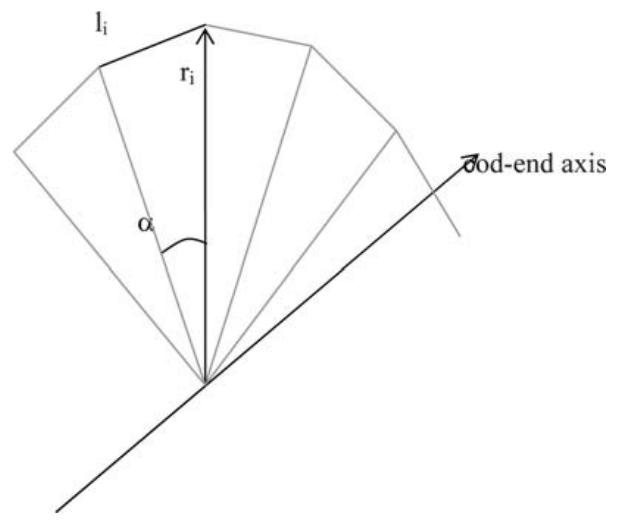

Fig. 5 Parallel twines along one circumference

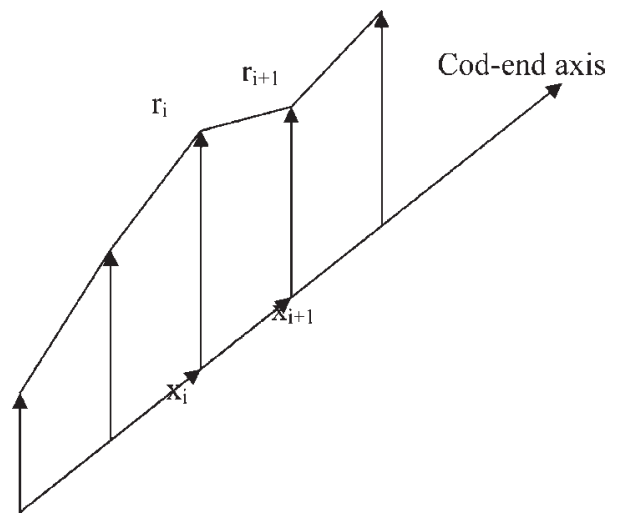

Fig. 6 Twines along one meridian 


\subsubsection{Rectangular-mesh cod-end}

The tensile forces acting on the nodes of a rectangular-mesh cod-end are similar to those acting on the nodes of a square-mesh cod-end, except that the circumferential and meridional mesh bars have a different unstretched length.

\subsubsection{Kite-mesh cod-end}

The tensile forces acting on the nodes of a kite-mesh cod-end are similar to those acting on the nodes of a diamond-mesh cod-end, except that the unstretched lengths of the forward and rear mesh bars of a kiteshaped mesh are different.

\subsection{Catch pressure}

The studies of O'Neill et al. [12] and Priour and Herrmann [4] demonstrate that the hydrodynamic forces that act on the catch in the cod-end result in the catch exerting a pressure force on the cod-end netting that can be described by

$$
P=\frac{1}{2} \rho C_{\mathrm{d}} V^{2}
$$

where $P$ is the pressure due to the catch $\left(\mathrm{N} / \mathrm{m}^{2}\right), \rho$ is the water density $\left(1025 \mathrm{~kg} / \mathrm{m}^{3}\right), C_{\mathrm{d}}$ is the drag coefficient on the catch $\left(C_{\mathrm{d}}=1.4,[13]\right)$, and $V$ is the towing speed $(\mathrm{m} / \mathrm{s})$. The axial and radial projections of the surface area associated with the node $i$ are (Fig. 7)

$$
S_{x, i}=\frac{\theta}{4}\left|r_{i+1}^{2}-r_{i-1}^{2}\right|
$$

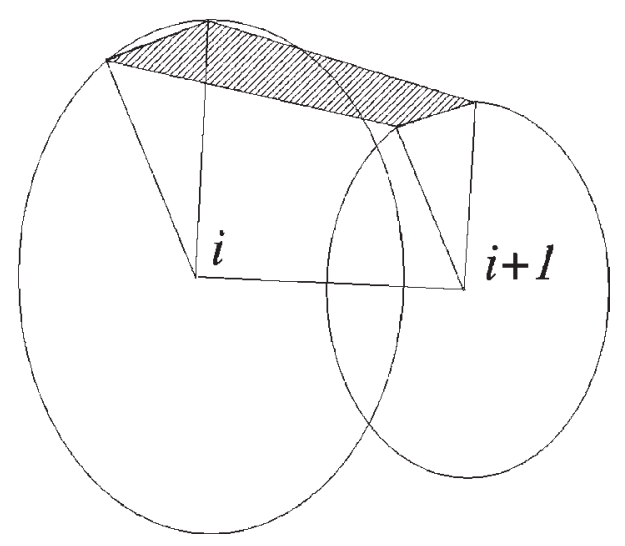

Fig. 7 Surface involved by the catch pressure for one twine

$$
S_{r, i}=\frac{\theta}{4}\left|\left(r_{i+1}+r_{i-1}\right)\left(x_{i+1}-x_{i-1}\right)\right|
$$

and hence the catch force acting on the netting at node $i$ can be given by

$$
\boldsymbol{P}_{i}=\frac{P \theta\left|r_{i+1}+r_{i-1}\right|}{4}\left(\begin{array}{c}
\left|r_{i+1}-r_{i-1}\right| \\
\left|x_{i+1}-x_{i-1}\right| \\
0
\end{array}\right)
$$

These equations also hold for cod-ends made of kite-, square-, and rectangular-shaped netting, where, for square and rectangular meshes, $\theta$ is replaced by $\alpha$.

\subsection{Solver}

The force components are summed at each node and the Newton-Raphson scheme is used to assess the equilibrium position. This method is an iterative method where, for each iteration $k$, the displacement of the nodes is calculated by the equation

$$
\boldsymbol{h}_{k}=\boldsymbol{F}\left(X_{k}\right)\left[-\mathbf{F}^{\prime}\left(X_{k}\right)\right]^{-1}
$$

where $\boldsymbol{h}$ is the displacement vector of the nodes (m), $\boldsymbol{F}(X)$ is the force vector on the nodes $(\mathrm{N})$, and $\boldsymbol{F}^{\prime}(X)$ is the stiffness matrix calculated as the derivative of $F$ relative to $X(\mathrm{~N} / \mathrm{m})$.

The position at the next iteration $(k+1)$ is then calculated by $X_{k+1}=X_{k}+h_{k}$. This process is repeated until the residual force, $\boldsymbol{F}(X)$, is less than a predefined amount.

Boundary conditions are set at each end, one that specifies the entry diameter to the cod-end and the other that sets it to zero at the last node where the cod-end is tied closed. It is also necessary to define an initial position of the nodes along the cod-end, which here is assumed to be a straight line between the fixed boundaries that is the length of one row of twines. Thus, the initial shape of the cod-end is a cone.

\section{RESULTS}

\subsection{Diamond-mesh cod-end}

A number of simulations were carried out to predict the geometry of cod-ends made from diamond, square-, rectangular-, and kite-shaped meshes. The results are presented in Figs 8 to 9. In the first of these (Fig. 8), the geometry of a diamond-mesh cod-end, 54.5 meshes in length and 50 meshes in circumference, with a full mesh size of $110 \mathrm{~mm}$ and a catch length of 


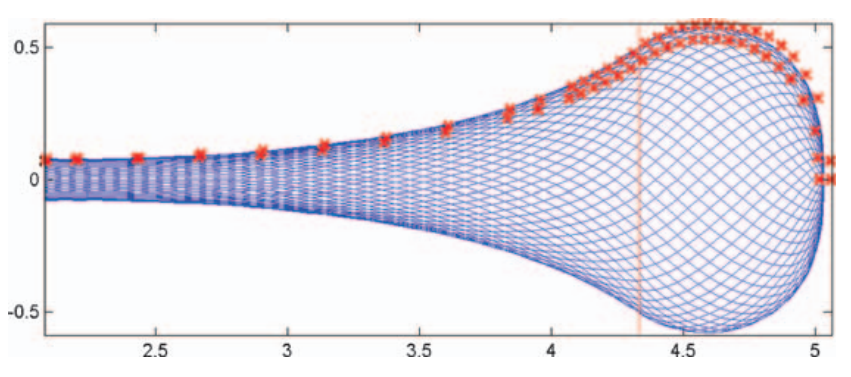

Fig. 8 Simulation of a diamond-mesh cod-end, 54.5 meshes in length, 50 meshes in circumference, with a full mesh size of $110 \mathrm{~mm}$ and a catch length of $0.70 \mathrm{~m}$. The crosses are experimental data from flume tank experiments [13]. The calculated volume is $0.591 \mathrm{~m}^{3}$ and the drag on the cod-end is $573 \mathrm{~N}$. Axes in $\mathrm{m}$

$0.70 \mathrm{~m}$, is shown. The catch length refers to the distance along the $x$ axis from the back of the codend where the catch blocks the cod-end netting. The volume calculated behind the front is $0.591 \mathrm{~m}^{3}$, and the calculated drag on the cod-end is $573 \mathrm{~N}$. These results are compared with experimental data from flume tank experiments [13] and are in good agreement.

\subsection{Square-mesh cod-end}

In Fig. 9 the geometry of a cod-end of square-mesh netting that is 124 meshes in length and 100 meshes in circumference is presented. The full mesh size (i.e. two bar lengths) of the netting is $100 \mathrm{~mm}$, and the catch length in this example is $2.222 \mathrm{~m}$. The calculated volume is $4.178 \mathrm{~m}^{3}$ and the drag on the cod-end is 5221 N. A comparison is made with the model of Priour $[\mathbf{8}]$, and again the results are in very good agreement.

\subsection{Rectangular-mesh cod-end}

Figure 10 shows the geometry of a rectangular-mesh cod-end. As in the last example, the cod-end is 124

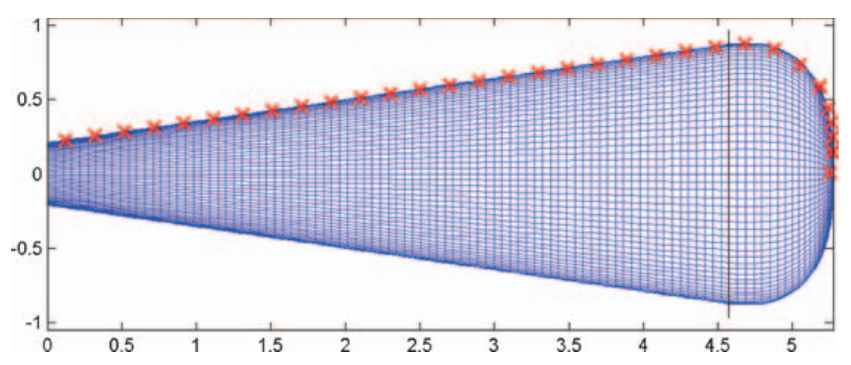

Fig. 9 Simulation of a square-mesh cod-end, 109 bars in length, 100 bars in circumference, with a full mesh size of $110 \mathrm{~mm}$ and a catch length of $0.70 \mathrm{~m}$. The crosses are from Priour's model [8]. The calculated volume is $1.345 \mathrm{~m}^{3}$ and the drag on the cod-end is $6340 \mathrm{~N}$. Axes in $\mathrm{m}$

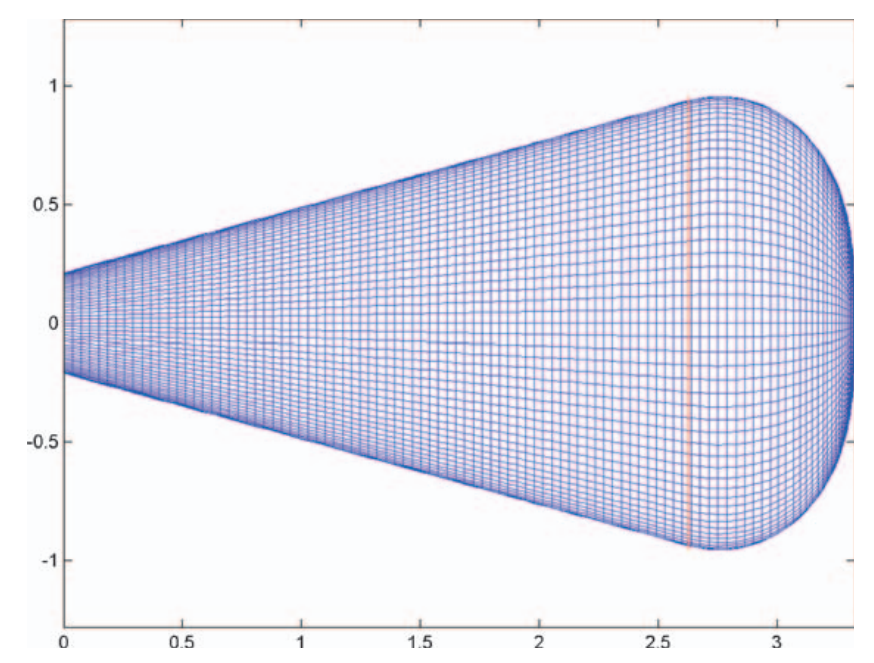

Fig. 10 Simulation of a rectangular-mesh cod-end, 109 bars in length, 100 bars in circumference, with a mesh bar of $38 \mathrm{~mm}$ along the meridian and $72 \mathrm{~mm}$ around the circumference and a catch length of $0.70 \mathrm{~m}$. The calculated volume is $1.554 \mathrm{~m}^{3}$ and the drag on the cod-end is 7314 N. Axes in $\mathrm{m}$

meshes in length and 100 meshes in circumference. The mesh size is again $100 \mathrm{~mm}$, but the mesh dimensions are such that the mesh bars in the direction of the cod-end length are $35 \mathrm{~mm}$ and those around the circumference are $65 \mathrm{~mm}$. The catch length is again $2.222 \mathrm{~m}$. Although the parameter values are similar to those of the square-mesh example in Fig. 9, the dimensions of the rectangular mesh used here result in an overall cod-end geometry that is shorter and wider.

\subsection{Kite-mesh cod-end}

The cod-end presented in Fig. 11 is made from kiteshaped netting where two of the mesh bars are $35 \mathrm{~mm}$ in length and the other two are $80.3 \mathrm{~mm}$, and

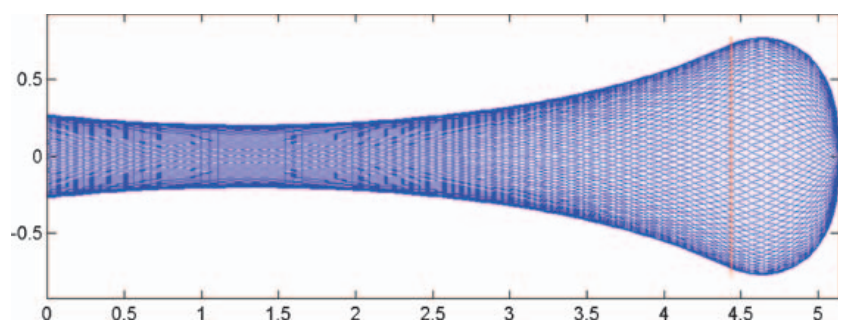

Fig. 11 Simulation of a kite-mesh cod-end, 54.5 meshes in length, 100 meshes in circumference, with mesh bar lengths of 38 and $72 \mathrm{~mm}$ and a catch length of $0.70 \mathrm{~m}$. The calculated volume is $1.033 \mathrm{~m}^{3}$ and the drag on the codend is $4302 \mathrm{~N}$. Axes in $\mathrm{m}$ 
the meshes are symmetrical across the meridians. Thus, the mesh size is $115.3 \mathrm{~mm}$. The cod-end has 50 meshes in length, 100 meshes in circumference, and a catch length of $1.133 \mathrm{~m}$. The effect of the kiteshaped mesh, relative to the diamond mesh, is to reduce the cod-end diameter in the region of the catch and slightly increase the cod-end length.

\section{DISCUSSION}

As can be seen from Figs 8 and 9, the results of the model presented in this paper agree very well with the cod-end geometries predicted by Priour's model [9] and measured in a flume tank. The only forces taken into account by this new model are the twine tensions and the catch force. A number of other factors such as twine bending stiffness and the hydrodynamic drag on the twines have not been considered. While O'Neill and O'Donoghue [11] have shown that the hydrodynamic drag on the twines is negligible in comparison with the catch pressure forces, twine bending stiffness can be important for netting made from polyethylene. This material is used by many sectors of the fishing industry, some of which have, in recent years, begun to use thicker and stiffer twines in the codend, leading to a reduction in selectivity of their fishing gears. The models of O'Neill [7] and Priour [9] can account for these factors, but they either depend on licensed software or are three-dimensional and relatively slow. The advantage of the model developed here is that it will be freely available and converges quickly (a few seconds for calculating the geometry of a given cod-end for a given catch size on a normal desktop computer). Hence, it is very suitable for use in situations where the geometry of a large number of different codend designs needs to be calculated over a wide range of catch weights and for incorporation into selectivity simulation models such as PRESEMO [2].

Nevertheless, to broaden its applicability and to be able to use it to predict the geometry of the full range of cod-ends used by the commercial fishing industry, the model is being developed to include twine bending stiffness and factors such as netting orientation and netting made from mesh shapes such as hexagonal.

It should also be possible to use this approach to examine the dynamic case. O'Neill et al. [14] have shown that sea-state-induced vessel motion can cause the cod-end to oscillate longitudinally, which may influence cod-end selection. A dy- namic model of the deformation of the cod-end has been developed by O'Neill and Neilson [15] but, as above, its solution depends on licensed software.

\section{REFERENCES}

1 Alverson, D. L. and Hughes, S. E. Bycatch: from emotion to effective natural resource management. In Solving bycatch: considerations for today and tomorrow (Ed. T. Wray), University of Alaska Sea Grant College Program, pp. 13-28 (University of alaska, Fairbanks, alaska).

2 Herrmann, B. Effect of catch size and shape on the selectivity of diamond mesh cod-ends: I Model development. Fish. Res., 2005, 71, 1-13.

3 O'Neill, F. G. and Herrmann, B. PRESEMO - a predictive model of codend selectivity - a tool for fishery managers. ICES J. Mar. Sci., 2007, 64, 1558-1568.

4 Priour, D. and Herrmann, B. Catch shape in codend. In Proceedings of the 7th International Workshop on Methods for the Development and Evaluation of Maritime Technologies, Busan, South Korea, 23-26 November 2005.

5 Herrmann, B. and O'Neill, F. G. Theoretical study of the between haul variation of haddock selectivity in a diamond mesh cod-end. Fish. Res., 2005, 74, 243-252.

6 O'Neill, F. G. Differential equations governing the geometry of a diamond mesh cod-end of a trawl net. Trans. ASME, J. Appl. Mechanics, 1997, 64(7), $7-14$.

7 O'Neill, F. G. Axisymmetric trawl cod-ends made from netting of a generalised mesh shape. IMA J. Appl. Math., 1999, 62, 245-262.

8 Priour, D. Calculation of net shapes by the finite element method with triangular elements. Commun. Numer. Meth., 1999, 15, 755-763.

9 Priour, D. Introduction of mesh resistance to opening in a triangular element for calculation of nets by the finite element method. Commun. Numer. Meth., 2001, 17, 229-237.

10 O'Neill, F. G. and Priour, D. Comparison and validation of two models of netting deformation. Trans. ASME, J. Appl. Mechanics.

11 O'Neill, F. G. and O'Donoghue, T. The fluid dynamic loading on catch and the geometry of trawl cod-ends. Proc. R. Soc. Lond. A, 1997, 453, 1631-1648.

12 O'Neill, F. G., Knudsen, L. H., Wileman, D. A., and McKay, S. J. Cod-end drag as a function of catch size and towing speed. Fish. Res., 2005, 72(2-3), 163-171.

13 Priour, D., O'Neill, F., Sala, A., Chevallier, P., and Hermann, B. PREMECS-II: Development of predictive model of cod-end selectivity, Final report, Contract Q5RS-2002-01328, 2006. 
14 O'Neill, F. G., McKay, S., Ward, J. N., Strickland, A., Kynoch, R. J., and Zuur, A. An investigation of the relationship between sea state induced vessel motion and cod-end selection. Fish. Res., 2003, 60, 107-130.
15 O'Neill, F. G., Neilson, R. D., O'Neill, F. G., and Neilson, R. D. A dynamic model of the deformation of a diamond mesh cod-end of a trawl net. Trans. ASME, J. Appl. Mechanics, 2008, 75(1). 